This item was submitted to Loughborough's Research Repository by the author.

Items in Figshare are protected by copyright, with all rights reserved, unless otherwise indicated.

\title{
Improved position offset based parameter determination of permanent magnet synchronous machines under different load conditions
}

PLEASE CITE THE PUBLISHED VERSION

http://dx.doi.org/10.1049/iet-epa.2016.0734

\section{PUBLISHER}

(c) The Institution of Engineering and Technology

\section{VERSION}

AM (Accepted Manuscript)

\section{PUBLISHER STATEMENT}

This work is made available according to the conditions of the Creative Commons Attribution-NonCommercialNoDerivatives 4.0 International (CC BY-NC-ND 4.0) licence. Full details of this licence are available at: https://creativecommons.org/licenses/by-nc-nd/4.0/

\section{LICENCE}

CC BY-NC-ND 4.0

\section{REPOSITORY RECORD}

Liu, Kan, Jianghua Feng, Shuying Guo, Lei Xiao, and Zi-Qiang Zhu. 2019. "Improved Position Offset Based Parameter Determination of Permanent Magnet Synchronous Machines Under Different Load Conditions". figshare. https://hdl.handle.net/2134/25012. 


\title{
Improved position offset based parameter determination of permanent magnet synchronous machines under different load conditions
}

\author{
Kan Liu ${ }^{1,2}$, Jianghua Feng ${ }^{3}$, Shuying Guo ${ }^{3}$, Lei Xiao ${ }^{3}$, Z.Q. Zhu $^{2}$ \\ ${ }^{1}$ Control Systems Group, Loughborough University, UK \\ ${ }^{2}$ Department of Electronic and Electrical Engineering, University of Sheffield, UK \\ ${ }^{3}$ China Railway Rolling Stock Corporation, Zhuzhou, China \\ *k.liu3@lboro.ac.uk
}

\begin{abstract}
This paper proposes a novel method for the parameter determination of permanent magnet (PM) synchronous machines under different load conditions. It can identify the total $d q$-axis flux linkages and also the PM flux linkage separately by the addition of a pair of negative and positive position offsets. It is also noteworthy that the influence of uncertain inverter nonlinearity and winding resistance is cancelled during the modelling process, and the experimental results on two different permanent magnet synchronous machines show a good agreement with the finite element prediction results. More importantly, it shows good performance in online tracking the variation of PM flux linkage, which is an important feature for aiding the condition monitoring of permanent magnets, for example, monitoring the temperature of PMs.
\end{abstract}

\author{
Nomenclature \\ $R$ \\ Stator winding resistance $(\Omega)$. \\ $L_{d}, L_{q} \quad d q$-axis inductances $(\mathrm{H})$. \\ $\psi_{m} \quad$ PM flux linkage $(\mathrm{Wb})$. \\ $\psi_{d}, \psi_{q} \quad d q$-axis flux linkages $(\mathrm{Wb})$ \\ $i_{d}, i_{q} \quad$ Real $d q$-axis currents (A). \\ $i_{a s}, i_{b s}, i_{b s} \quad$ Stator abc phase currents (A). \\ $i_{d 1}^{\prime}, i_{q 1}^{\prime}, u_{d 1}^{\prime}, u_{q 1}^{\prime} \quad d q_{1}$-axis currents and voltages \\ $i_{d 2}^{\prime}, i_{q 2}^{\prime}, u_{d 2}^{\prime}, u_{q 2}^{\prime} \quad d q_{2}$-axis currents and voltages. \\ $i_{d 1}, i_{q 1}, u_{d 1}, u_{q 1} \quad d q$-axis currents and voltages correspond to the addition of $\Delta \theta_{p}$. \\ $i_{d 2}, i_{q 2}, u_{d 2}, u_{q 2} \quad d q$-axis currents and voltages correspond to the addition of $\Delta \theta_{n}$. \\ $u_{d}, u_{q} \quad$ Real $d q$-axis voltages $(\mathrm{V})$. \\ $u_{d}^{*}, u_{q}^{*} \quad d q$-axis reference voltages obtained from PI regulators $(\mathrm{V})$. \\ $u_{d 1}^{*}, u_{q 1}^{*}, u_{d 2}^{*}, u_{q 2}^{*} \quad d q_{1}$-axis and $d q_{2}$-aixs reference voltages obtained from PI regulators $(\mathrm{V})$.
}


$V_{\text {dead }}, V_{\text {dead } 1}^{\prime}, V_{\text {dead } 2}^{\prime} \quad$ Distorted voltages due to inverter nonlinearity on $d q^{-}, d q_{1}$ - and $d q_{2}$ - axes (V).

$D_{d}, D_{q} \quad$ Gains of distorted voltages due to inverter nonlinearity on $d q$-axes.

$\omega, \theta \quad$ Electrical angular speed $(\mathrm{rad} / \mathrm{s})$ and position (rad).

$\Delta \theta_{n}, \Delta \theta_{p} \quad$ Added negative and positive position offsets, respectively (rad).

$D_{d 1}^{\prime}, D_{q 1}^{\prime}, D_{d 2}^{\prime}, D_{q 2}^{\prime} \quad$ Gains of distorted voltages due to inverter nonlinearity on $d q_{1}$ - and $d q_{2}$-axes.

\section{Introduction}

Electrical parameters of permanent magnet synchronous machines (PMSMs) are usually needed in industrial drives such as maximum torque per ampere (MTPA) control, flux weakening (FW) control [1]-[3], sensorless control [4]-[10], condition monitoring [9], [11], and derivation of constants of PI regulators [12], [13]. Therefore, in reality, it is of significant importance that the determination of the real parameter model of PMSM should be conducted prior to the design of control systems. However, it is reported in [14] and [15] that the PMSM equation is rank-deficient and it is impossible to obtain all machine parameters in the circuit model simultaneously. Thus, it is usually necessary to add perturbations [16], [17] or change the working point of PMSM [18] to obtain more sets of equations to overcome this issue. Besides, the voltage source inverter (VSI) nonlinearity should also be considered and well compensated or cancelled in the algorithm [18]-[20].

Taking the load test method as an example, it is one of the most conventional solutions for the determination of $d q$-axis inductances and PM flux linkage over the whole range of operation [21]-[24]. It is based on the assumption that the variation of those parameters will be negligible if there is a small change in the $d$-axis current. However, as investigated in [22], the estimation model of load test method is usually ill-conditioned due to the too small perturbation and a significant error may be introduced into the calculation results. Thus, the amplitude of added perturbation needs to be optimized prior to the startup of load test [21], [22].

In addition to the load test method, it is also a simple solution to reduce the number of unknown parameters by setting some machine parameters to their nominal values, by which the rank deficient issue is consequently overcome [25]. However, this type of method is still easy to suffer from the mismatching between the nominal and real machine parameters and the accuracy of calculated variation of machine parameters will be significantly influenced by this mismatching [14]. For example, the method reported in [25] sets the rotor PM flux linkage to its nominal value, by which the number of unknown parameters is reduced while the $d q$-axis inductances are estimated afterwards. However, the saturation level of the magnetic circuit will be changed after the loading of the electrical machine, which will result in changes in both the PM flux linkage and inductance 
[26], [27]. Nevertheless, this type of method sets either of them to be constant and its accuracy will therefore always be influenced due to this simplification.

Besides, the identification of magnetic model of PMSM is also reported recently [28]-[32], in which two lumped variables, viz. $d q$-axis flux linkages, are used to represent the total contributions of permanent magnets and inductances to the machine equation [27]. This kind of method can be conducted at standstill with a rotor locked [28], [29] or by a motor-brake test [30], [31]. For example, a motor-brake average method is proposed in [30] and it uses a three-pulse evaluation to cancel the influence of temperature rise in stator winding. However, it needs to design special voltage measurement equipment to avoid the influence of inverter nonlinearity. An improvement to this method is proposed in [31], which estimates the winding resistance and the influence of inverter nonlinearity at standstill to aid the identification of flux linkages and consequently avoid the investment on extra measurement equipment. However, this type of method still cannot individually obtain the PM flux linkage under all load conditions.

Recently, the position offset based parameter estimation (POPE) scheme for PMSMs has been reported [19], [20] and shows quite good performance in the estimation of PM flux linkage under $i_{d}=0$ control. However, this scheme cannot be applied to the estimation of PM flux linkage at $i_{d} \neq 0$ because it needs $i_{d}=0$ to eliminate the influence of saliency term. Thus, this issue has been investigated in this paper, and an improved POPE is proposed to estimate and compensate this saliency term, by which the PM flux linkage can be consequently estimated at $i_{d} \neq 0$. Furthermore, it has eliminated the influence of inverter nonlinearity and winding resistance on the determination of PM flux linkage and total $d q$-axis flux linkages during the modeling process and has the potential to be used for online monitoring of the demagnetization in PMs due to temperature rise. Its performance is then experimentally evaluated on a surface mounted PMSM (SPMSM) and an interior PMSM (IPMSM), respectively, while a good agreement with the finite element (FE) result is achieved.

\section{Modelling of position offset based parameter}

\subsection{Modelling of PMSM and Rank Deficient Problem}

In the $d q$-axis reference frame, the voltage equation of PMSM can be expressed as follows:

$$
\begin{aligned}
& u_{d}=R i_{d}-L_{q} \omega i_{q}+L_{d} \frac{d i_{d}}{d t} \\
& u_{q}=R i_{q}+L_{d} \omega i_{d}+\psi_{m} \omega+L_{q} \frac{d i_{q}}{d t}
\end{aligned}
$$

At the steady state of operation, (1) can be rewritten as (2) by taking into account the inverter nonlinearity [33], [34]: 
$u_{d}^{*}+V_{\text {dead }} D_{d}=u_{d}=R i_{d}-L_{q} i_{q} \omega$

$u_{q}^{*}+V_{\text {dead }} D_{q}=u_{q}=R i_{q}+\psi_{m} \omega+L_{d} i_{d} \omega$

From (2), it is obvious that there are four unknown machine parameters $\left(L_{d}, L_{q}, R\right.$ and $\left.\psi_{m}\right)$ and an unknown voltage term $V_{\text {dead }}$ in the equation. In this case, there will be a rank deficient problem and it is impossible to simultaneously solve all those unknown parameters from (2). Besides, the term $V_{\text {dead }}$ has included the influence of switch on/off time delay $\left.\left(T_{o n}, T_{o f f}\right)\right)$, dead time $\left(T_{d}\right)$, on-state voltage drops due to $\operatorname{IGBT}\left(V_{c e 0}\right)$ and diode $\left(V_{d 0}\right)$ and can be expressed as [33], [34]:

$V_{\text {dead }}=\frac{1}{6}\left(\frac{T_{o f f}-T_{o n}-T_{d}}{T_{s}} V_{d c}-V_{c e 0}-V_{d 0}\right)$

It should be emphasized that $T_{\text {on }}$ and $T_{\text {off }}$ have already included the average contribution of the time delay due to the effect of the parasitic capacitances of inverter [35]. $D_{d}$ and $D_{q}$ can be expressed as [33], [34]:

$$
\begin{aligned}
& {\left[\begin{array}{l}
D_{d} \\
D_{q}
\end{array}\right]=2\left[\begin{array}{ccc}
\cos (\theta) & \cos \left(\theta-\frac{2 \pi}{3}\right) & \cos \left(\theta+\frac{2 \pi}{3}\right) \\
-\sin (\theta) & -\sin \left(\theta-\frac{2 \pi}{3}\right) & \sin \left(\theta-\frac{\pi}{3}\right)
\end{array}\right]\left[\begin{array}{l}
\operatorname{sign}\left(i_{a s}\right) \\
\operatorname{sign}\left(i_{b s}\right) \\
\operatorname{sign}\left(i_{c s}\right)
\end{array}\right]} \\
& \operatorname{sign}(i)=\left\{\begin{array}{l}
1, i>=0 \\
-1, i<0
\end{array}\right.
\end{aligned}
$$

\subsection{Position offset based determination}

As discussed in section 2.1, it is not possible to derive $d q$-axis inductances and PM flux linkage directly from one set of PMSM equation due to rank deficient issue and unknown inverter nonlinearity term. In order to solve this issue, a new method based on the addition of two position offsets $\Delta \theta=-\Delta \theta_{n}=\Delta \theta_{p}$ into the conventional field oriented drive is proposed in this section, by which the $d q$-axis inductances and PM flux linkage can be separately determined while the influence of uncertain inverter nonlinearity and winding resistance is cancelled during the modelling process. Its principle and derivation are introduced below:

Fig. 1 shows the phasor diagram of PMSM voltage with and without the addition of position offset $\Delta \theta$ into the encoder reading. Assuming that the reference currents of $d q$-axis regulators are fixed to constants and the rotor speed is tuned by the external load, for example, a DC load machine, two sets of PMSM data (Data1 and Data2) corresponding to the addition of two position offsets $\Delta \theta_{p}=-\Delta \theta_{n}=\Delta \theta$ to encoder readings, respectively, can be obtained at the steady state of operation, by which two sets of $d q$-axis equations can also be derived according to Fig. 1 and shown in (6): 


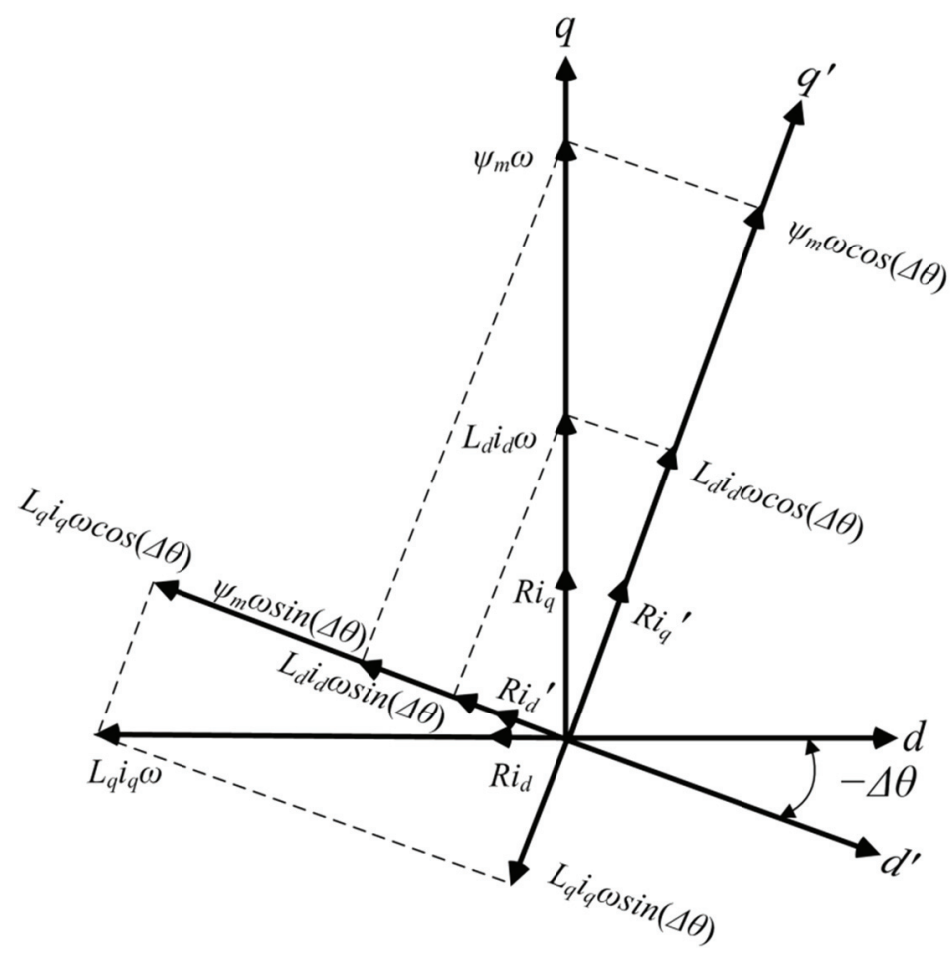

Fig. 1.Phasor diagram of PMSM with and without position offset $\Delta \theta$ at steady state.

$u_{d 1}^{\prime}=u_{d 1}^{*}+V_{d e a d 1}^{\prime} D_{d 1}^{\prime}=R i_{d 1}^{\prime}+\omega_{1}\left(\psi_{m} \sin (\Delta \theta)+L_{d} i_{d 1} \sin (\Delta \theta)-L_{q} i_{q 1} \cos (\Delta \theta)\right)$

$u_{q 1}^{\prime}=u_{q 1}^{*}+V_{\text {dead } 1}^{\prime} D_{q 1}^{\prime}=R i_{q 1}^{\prime}+\omega_{1}\left(\psi_{m} \cos (\Delta \theta)+L_{d} i_{d 1} \cos (\Delta \theta)+L_{q} i_{q 1} \sin (\Delta \theta)\right)$

$u_{d 2}^{\prime}=u_{d 2}^{*}+V_{d e a d 2}^{\prime} D_{d 2}^{\prime}=R i_{d 2}^{\prime}-\omega_{2}\left(\psi_{m} \sin (\Delta \theta)+L_{d} i_{d 2} \sin (\Delta \theta)+L_{q} i_{q 2} \cos (\Delta \theta)\right)$

$u_{q 2}^{\prime}=u_{q 2}^{*}+V_{\text {dead } 2}^{\prime} D_{q 2}^{\prime}=R i_{q 2}^{\prime}+\omega_{2}\left(\psi_{m} \cos (\Delta \theta)+L_{d} i_{d 2} \cos (\Delta \theta)-L_{q} i_{q 2} \sin (\Delta \theta)\right)$

where (6a) and (6b) correspond to the addition of $\Delta \theta_{p}=\Delta \theta$ while (6c) and (6d) correspond to the addition of $\Delta \theta_{n}=-\Delta \theta$. For the convenience of analysis, the two new $d q$-axis reference frames corresponding to $\Delta \theta_{p}$ and $\Delta \theta_{n}$ are designated as $d q_{1^{-}}$-axis and $d q_{2^{-}}$ axis, respectively. Since the values of $\Delta \theta_{p}$ and $\Delta \theta_{n}$ are quite small, it is reasonable to assume that the machine parameters such as the winding resistance $R$, PM flux linkage $\psi_{m}$ and $d q$-axis inductances $L_{d}, L_{q}$ will not change due to the addition of position offsets. Besides, the rotor speed is tuned to be $\omega_{1}=\omega_{2}=\omega$ at the steady state by changing the external load, for example, the DC load machine. The superscript ' means that the variable is on the $d q_{1}$-axis or $d q_{2}$-axis. The detailed definitions of variables in (6) are listed in the nomenclature. Besides, for the POPE, the reference currents are fixed by the PI regulators, the relationship between $i_{d 1}^{\prime}, i_{q 1}^{\prime}, i_{d 2}^{\prime}, i_{q 2}^{\prime}, i_{d 1}, i_{q 1}, i_{d 2}$ and $i_{q 2}$ are detailed as follows:

$i_{d 2}^{\prime}=i_{d 1}^{\prime}, i_{q 2}^{\prime}=i_{q 1}^{\prime}$ 
$i_{d 1}=i_{d 1}^{\prime} \cos (\Delta \theta)-i_{q 1}^{\prime} \sin (\Delta \theta)$

$i_{d 2}=i_{q 2}^{\prime} \sin (\Delta \theta)+i_{d 2}^{\prime} \cos (\Delta \theta)$

$i_{q 1}=i_{q 1}^{\prime} \cos (\Delta \theta)+i_{d 1}^{\prime} \sin (\Delta \theta)$

$i_{q 2}=i_{q 2}^{\prime} \cos (\Delta \theta)-i_{d 2}^{\prime} \sin (\Delta \theta)$

Besides, since the VSI nonlinearity term $V_{\text {dead }} D_{d}$, and $V_{\text {dead }} D_{q}$ are functions of currents on the rotating reference frames such as $d q^{-}, d q_{1-}$, and $d q_{2^{-}}$axes, it is reasonable that $\operatorname{mean}\left(V_{\text {dead } 1}^{\prime} D_{d 1}^{\prime}\right)=\operatorname{mean}\left(V_{\text {dead } 2}^{\prime} D_{d 2}^{\prime}\right)$ and $\operatorname{mean}\left(V_{\text {dead } 1}^{\prime} D_{q 1}^{\prime}\right)=\operatorname{mean}\left(V_{\text {dead } 2}^{\prime} D_{q 2}^{\prime}\right)[33]$

[34], of which 'mean' is the mean operator. Assuming that $i_{d 2}^{\prime}=i_{d 1}^{\prime}=i_{d}^{\prime}$ and $i_{q 2}^{\prime}=i_{q 1}^{\prime}=i_{q}^{\prime},(6 \mathrm{a})$-(6c) yields:

$\operatorname{mean}\left(u_{d 1}^{*}-u_{d 2}^{*}\right)=\operatorname{mean}\left[2 \psi_{m} \omega \sin (\Delta \theta)+L_{d} \omega \sin (\Delta \theta)\left(i_{d 1}+i_{d 2}\right)+L_{q} \omega \cos (\Delta \theta)\left(i_{q 2}-i_{q 1}\right)\right]$

$=\operatorname{mean}\left[2 \psi_{m} \omega \sin (\Delta \theta)+\left(L_{d}-L_{q}\right) i_{d}^{\prime} \omega \sin (2 \Delta \theta)\right]$

From (8), it is obvious that there is a saliency term $\left(L_{d}-L_{q}\right) i_{d}^{\prime} \omega \sin (2 \Delta \theta)$ in the equation, which may result in a significant error in the estimation of PM flux linkage $\psi_{m}$ if $i_{d} \neq 0$. In order to eliminate this issue, a solution is developed and introduced below:

Similar to the derivation of $(8),(6 b)-(6 d)$ yields:

$\operatorname{mean}\left(u_{q 1}^{*}-u_{q 2}^{*}\right)=\operatorname{mean}\left[L_{d} i_{d 1} \omega \cos (\Delta \theta)-L_{d} i_{d 2} \omega \cos (\Delta \theta)+L_{q} i_{q 1} \omega \sin (\Delta \theta)+L_{q} i_{q 2} \omega \sin (\Delta \theta)\right]$

$=\operatorname{mean}\left[\left(L_{q}-L_{d}\right) i_{q}^{\prime} \omega \sin (2 \Delta \theta)\right]$

It also should be emphasized that $\left(L_{q}-L_{d}\right) \operatorname{mean}\left[i_{q}^{\prime} \omega \sin (2 \Delta \theta)\right]=\operatorname{mean}\left[\left(L_{q}-L_{d}\right) i_{q}^{\prime} \omega \sin (2 \Delta \theta)\right]$ because $L_{q}-L_{d}$ can be regarded as a constant at a fixed load point. Thus, the saliency term $L_{q}-L_{d}$ can be obtained by:

$\Delta L=L_{q}-L_{d}=\frac{\operatorname{mean}\left(u_{q 1}^{*}-u_{q 2}^{*}\right)}{\operatorname{mean}\left(i_{q}^{\prime} \omega \sin (2 \Delta \theta)\right)}$

Besides, since the data measurement is at steady state, it is reasonable that real machine parameters and measured $u_{q 1}^{*}, u_{q 2}^{*}, i_{q}^{\prime}$, $\omega, i_{d}^{\prime}$ are almost constant in all equations. Thus, (11) can be derived from (10):

$\frac{\operatorname{mean}\left[\left(u_{q 1}^{*}-u_{q 2}^{*}\right) i_{d}^{\prime}\right]}{\operatorname{mean}\left(i_{q}^{\prime}\right)}=\operatorname{mean}\left[\left(L_{q}-L_{d}\right) i_{d}^{\prime} \omega \sin (2 \Delta \theta)\right]$ 
Table I Design parameters and specification of PMSMs

\begin{tabular}{lll}
\hline Parameters & Motor1 & Motor2 \\
\hline Rated current & $4 \mathrm{~A}$ & $10 \mathrm{~A}$ \\
Rated speed & $1000 \mathrm{rpm}$ & $400 \mathrm{rpm}$ \\
DC link voltage & $158 \mathrm{~V}$ & $36 \mathrm{~V}$ \\
Nominal phase resistance $\left(T=15^{\circ} \mathrm{C}\right)$ & $6.00 \Omega$ & $0.30 \Omega$ \\
Nominal $d$-axis inductance $(T h e$ end effects are considered for Motor1) & $38.10 \mathrm{mH}$ & $3.24 \mathrm{mH}$ \\
Nominal $q$-axis inductance $(T h e$ end effects are considered for Motor1) & $58.50 \mathrm{mH}$ & $3.24 \mathrm{mH}$ \\
Nominal PM flux linkage $\left(T=15^{\circ} \mathrm{C}\right)$ & $236.0 \mathrm{mWb}$ & $70.7 \mathrm{mWb}$ \\
Number of pole pairs & 3 & 5 \\
Number of stator slots & 18 & 12 \\
\hline
\end{tabular}

Note: Nominal values are measured.

Table II Influence of position offset on $d q$-axis rotor flux linkage terms of Motor1

\begin{tabular}{ccc}
\hline$\Delta \theta=\mathrm{n} \theta_{u}$ & $\psi_{m} \omega \cos (\Delta \theta)$ & $\psi_{m} \omega \sin (\Delta \theta)$ \\
$\mathrm{n}=2$ & $0.9998 \psi_{m} \omega$ & $0.0184 \psi_{m} \omega$ \\
$\mathrm{n}=5$ & $0.9989 \psi_{m} \omega$ & $0.0460 \psi_{m} \omega$ \\
$\mathrm{n}=10$ & $0.9958 \psi_{m} \omega$ & $0.0919 \psi_{m} \omega$ \\
$\mathrm{n}=20$ & $0.9831 \psi_{m} \omega$ & $0.1830 \psi_{m} \omega$ \\
\hline
\end{tabular}

Note: The maximum number of lines of encoder of Motor1 is $M=2048$.

Substituting (11) into (8) yields:

$\operatorname{mean}\left(u_{d 1}^{*}-u_{d 2}^{*}\right)+\frac{\operatorname{mean}\left[\left(u_{q 1}^{*}-u_{q 2}^{*}\right) i_{d}^{\prime}\right]}{\operatorname{mean}\left(i_{q}^{\prime}\right)}=2 \psi_{m} \sin (\Delta \theta) \operatorname{mean}(\omega)$

Thus, the rotor PM flux linkage under $i_{d} \neq 0$ can be solved from (12):

$\psi_{m}=\frac{\operatorname{mean}\left(u_{d 1}^{*}-u_{d 2}^{*}\right)}{2 \sin (\Delta \theta) \operatorname{mean}(\omega)}+\frac{\operatorname{mean}\left[\left(u_{q 1}^{*}-u_{q 2}^{*}\right) i_{d}^{\prime}\right]}{2 \sin (\Delta \theta) \operatorname{mean}\left(i_{q}^{\prime} \omega\right)}$

In order to ensure a high ratio of signal versus noise, it is suggested that the added $\Delta \theta$ can ensure that the dominant term $u_{d 1}^{*}-u_{d 2}^{*} \geq 0.2 \mathrm{~V}$ or $\left|\psi_{m} \omega \sin (\Delta \theta)\right| \geq 0.1 \mathrm{~V}$, which is similar to that of [19]. As a summary to the process of (6)-(13), the proposed method is based on assumptions below, which are reasonable in reality:

a) Since the time for the data measurement at each load point is usually quite short and the machine is running at steady state, it is reasonable to assume that the circuit resistance including iron loss resistance, winding resistance and on-state resistance of power device will not change during the measurement process. Thus, the proposed method is irrespective of the winding resistance and temperature rise in winding.

b) Similarly, the temperature of PM flux linkage will also be regarded as a constant during the data measurement (in this paper, 2 seconds for data measurement at each load point).

c) The rotor speed and $d q$-axis reference currents are set to constants during the data measurement.

\subsection{Calculation of dq-axis flux linkages}




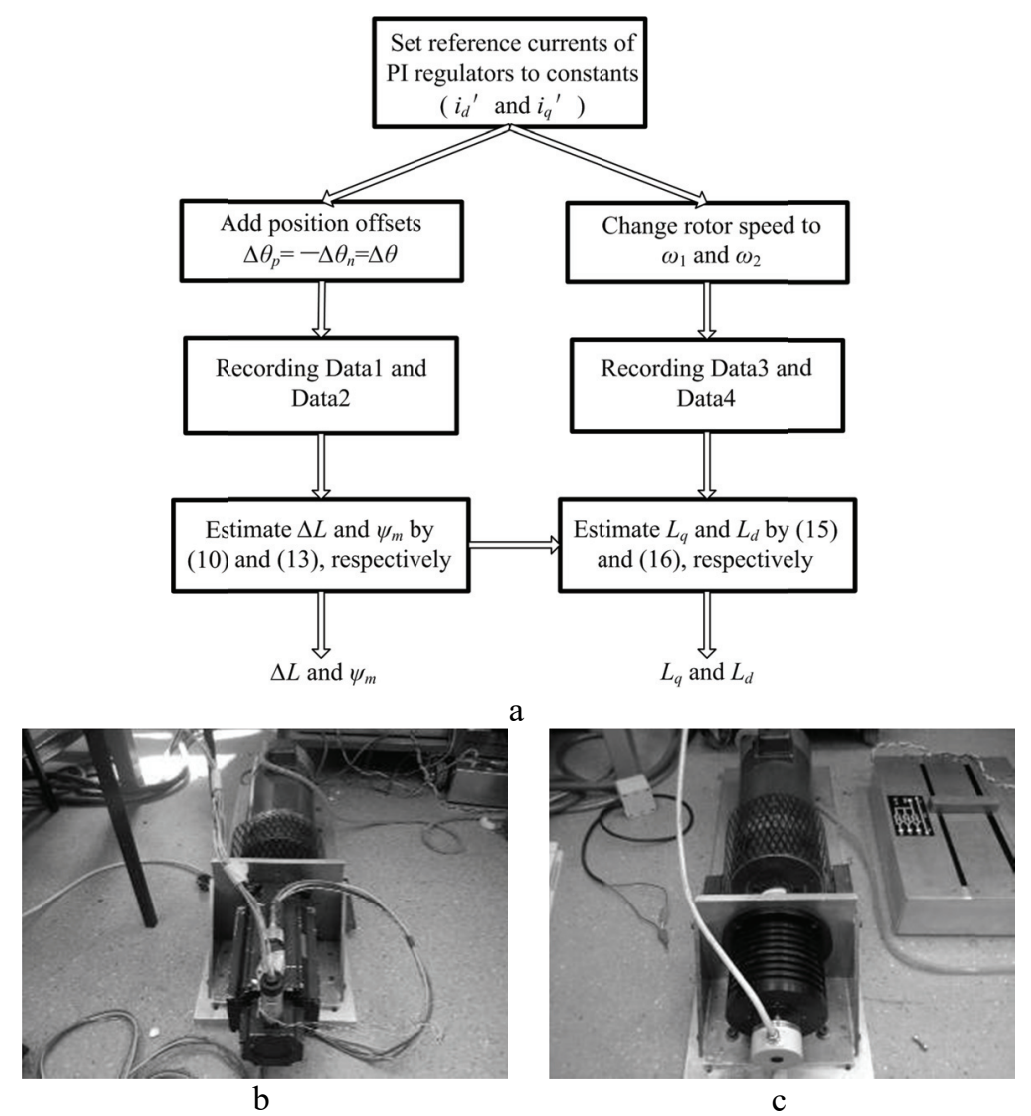

Fig. 2.Proposed method and test bench for two PMSMs.

a Schematic diagram of proposed improved POPE for PMSMs

b Motor 1

c Motor2

Since the saliency term $\Delta L=L_{q}-L_{d}$ can be calculated from (10), $L_{d}$ can be then obtained once $L_{q}$ is estimated. A simple solution for the estimation of $L_{q}$ at different load conditions is introduced here.

On condition that the $d q$-axis reference currents are set to constants and $\Delta \theta=0$, the rotor speed is set to two different rotor speeds by tuning the load, for example, a DC load machine. Two sets of data (Data3 and Data4) corresponding to the two rotor speeds at steady state will be recorded, by which two $d$-axis equations can be obtained:

$u_{d 3}=u_{d 3}^{*}+V_{d e a d 3} D_{d 3}=R i_{d 3}-L_{q} i_{q 3} \omega_{3}$

$u_{d 4}=u_{d 4}^{*}+V_{\text {dead } 4} D_{d 4}=R i_{d 4}-L_{q} i_{q 4} \omega_{4}$

where $i_{d 3}=i_{d 4}=i_{d}^{\prime}, i_{q 3}=i_{q 4}=i_{q}^{\prime} . \omega_{3}$ and $\omega_{4}$ are electrical angular speeds corresponding to two different rotor speeds. Similarly, since the $d q$-axis currents are fixed as constants, it is reasonable that mean $\left(V_{d e a d 3}^{\prime} D_{d 3}^{\prime}\right)=\operatorname{mean}\left(V_{d e a d 4}^{\prime} D_{d 4}^{\prime}\right)$ and mean $\left(V_{d e a d 3}^{\prime} D_{q 3}^{\prime}\right)$ $=$ mean $\left(V_{\text {dead } 4}^{\prime} D_{q 4}^{\prime}\right)$. Thus, $(14 \mathrm{a})-(14 \mathrm{~b})$ yields:

$\operatorname{mean}\left(u_{d 3}^{*}-u_{d 4}^{*}\right)=L_{q} \operatorname{mean}\left[i_{q}^{\prime}\left(\omega_{4}-\omega_{3}\right)\right]$ 


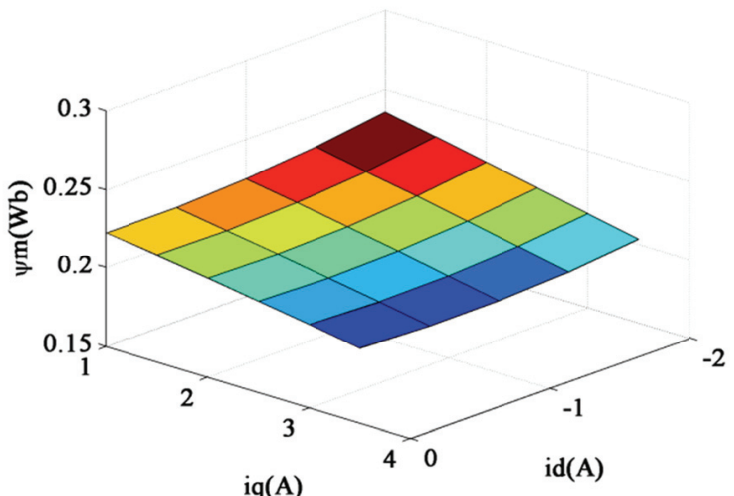

a

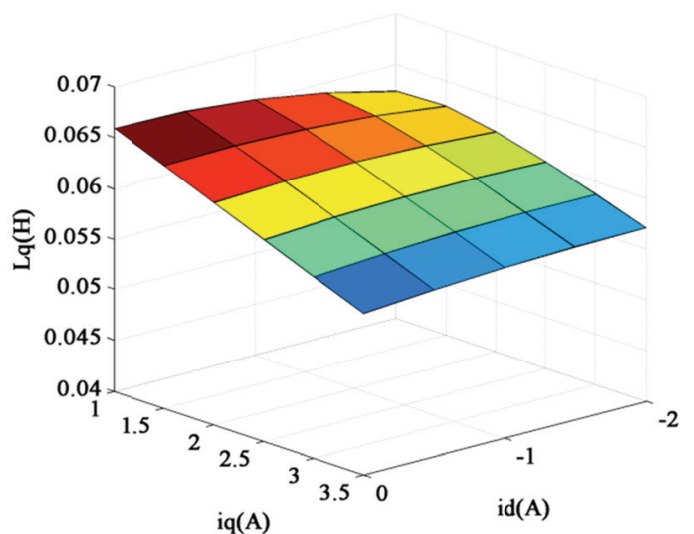

c
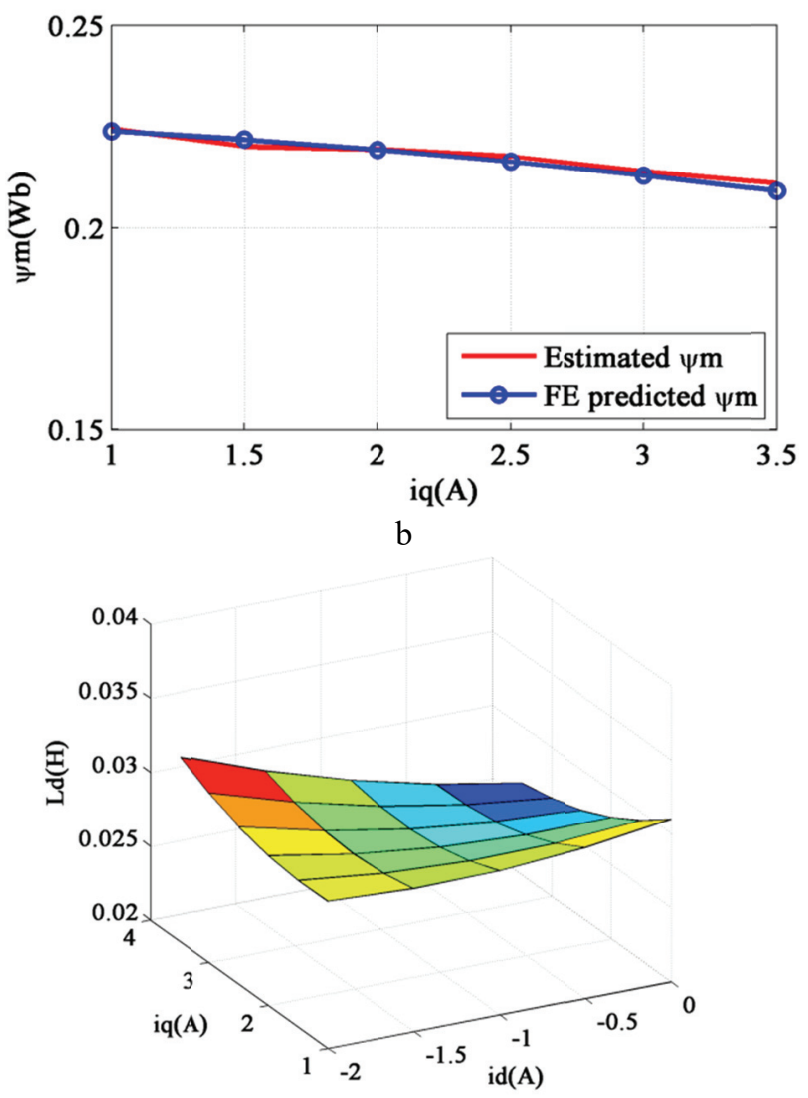

d

Fig. 3. Estimated PM flux linkage and $d q$-axis inductances by POPE (Motor1).

$\mathrm{a}, \mathrm{c}$, and d Estimated PM flux linkage, $d q$-axis inductances under different load conditions

$\mathrm{b}$ Comparison between POPE estimated and FE predicted PM flux linkages at $i_{d}=0$

$L_{q}=\frac{\operatorname{mean}\left(u_{d 3}^{*}-u_{d 4}^{*}\right)}{\operatorname{mean}\left[i_{q}^{\prime}\left(\omega_{4}-\omega_{3}\right)\right]}$

Thus, the $d$-axis inductance can also be obtained by:

$L_{d}=L_{q}-\Delta L$

It is suggested that in order to ensure a high ratio of signal versus noise, the difference between two rotor speeds $\omega_{3}-\omega_{4}$ needs to ensure the resulting change in $d$-axis voltage $u_{d 3}^{*}-u_{d 4}^{*} \geq 0.1 \mathrm{~V}$.

As a summary of the proposed method, the whole process of data measurement and calculation is detailed in Fig. $2 \mathrm{a}$, by which the saliency term, PM flux linkage and $d q$-axis inductances can be estimated by (10), (13), (15), and (16), respectively. With the estimated machine parameters, the $d q$-axis flux linkages can be therefore calculated by:

$\psi_{d}=L_{d} i_{d}+\psi_{m}$

$\psi_{q}=L_{q} i_{q}$ 


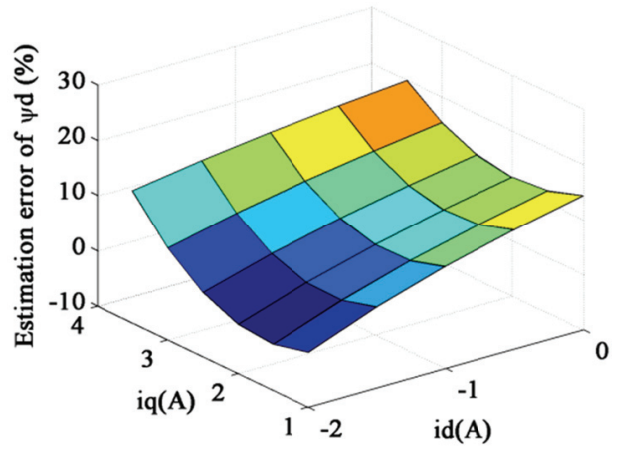

a

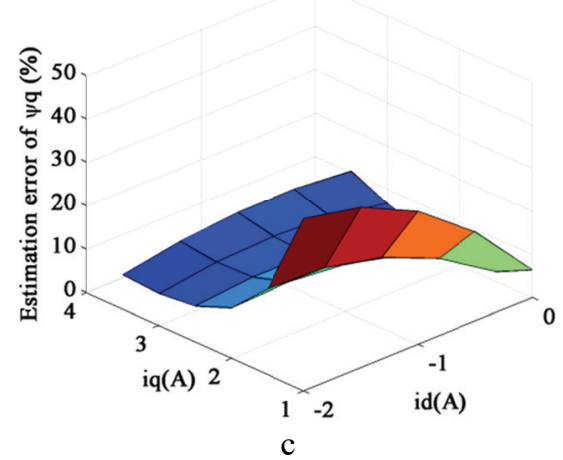

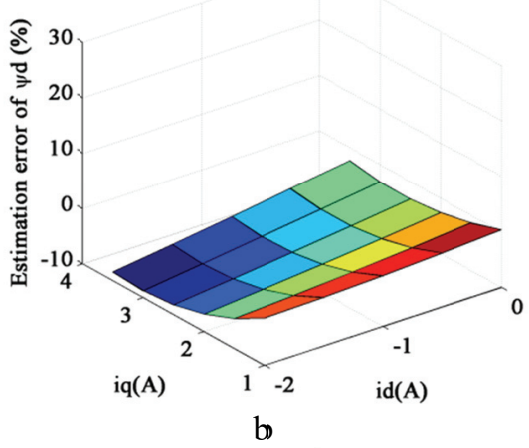

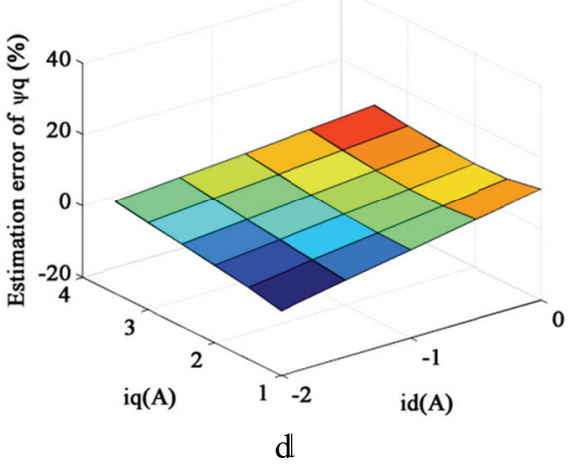

Fig. 4.Difference between estimation and FE results (Motor1).

$\mathrm{a}$ and $\mathrm{c}$ Estimation error of constant speed method compared with FE prediction (MAE of $\Delta \psi_{d}=9.53 \%$, MAE of $\Delta \psi_{q}=12.67 \%$ ). $\mathrm{b}$ and $\mathrm{d}$ Estimation error of POPE method compared with FE prediction (MAE of $\Delta \psi_{d}=4.29 \%$, MAE of $\Delta \psi_{q}=6.39 \%$ ).

Table III Comparison among three sets of test results on Motor 1

\begin{tabular}{ccccc}
\hline & & Minimum error & Maximum error & Mean absolute error \\
\hline Constant & $\Delta \psi_{d}$ & $\leq 0.5 \%$ & $19.98 \%$ & $9.53 \%$ \\
\cline { 2 - 5 } speed method & $\Delta \psi_{q}$ & $6.39 \%$ & $39.79 \%$ & $12.67 \%$ \\
\hline \multirow{2}{*}{ POPE method } & $\Delta \psi_{d}$ & $\leq 0.5 \%$ & $8.74 \%$ & $4.29 \%$ \\
\cline { 2 - 5 } & $\Delta \psi_{q}$ & $\leq 0.5 \%$ & $11.86 \%$ & $6.39 \%$ \\
\hline Nominal & $\Delta \psi_{d}$ & $\leq 0.5 \%$ & $12.84 \%$ & $4.39 \%$ \\
\cline { 2 - 5 } value method & $\Delta \psi_{q}$ & $\leq 0.5 \%$ & $17.11 \%$ & $5.79 \%$ \\
\hline
\end{tabular}

\section{Experimental results and Investigation}

\subsection{Test bench, prototype PMSM and experiment requirements}

It should be emphasized that the proposed method works in a field oriented PMSM drive system with a rotor position sensor. At each load point of data measurement, the $d q$-axis currents should be set to constants by the $d q$-axis current regulators while the rotor speed is tuned to be constant by the external load, for example, a load machine.

Thus, the two prototype PMSMs, being designated as Motor1 and Motor2 and depicted in Figs. 2b and 2c, respectively, will be investigated in this paper and controlled by a conventional IGBT based field oriented drive. Besides, a permanent magnet DC machine, of which the torque and speed are tuned by a variable sliding resistor, is employed as the external load. 


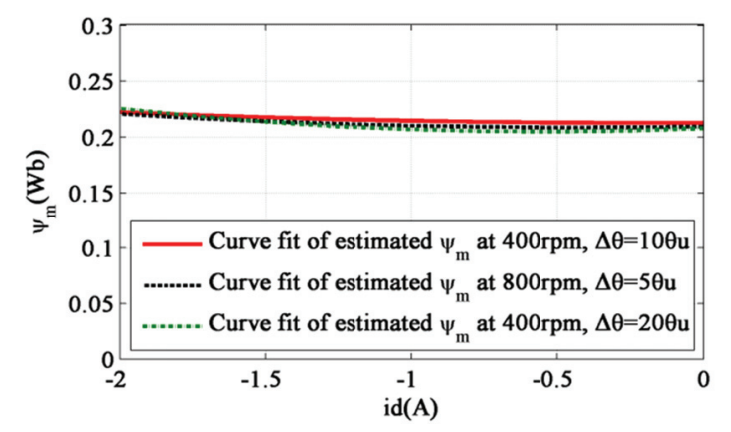

a

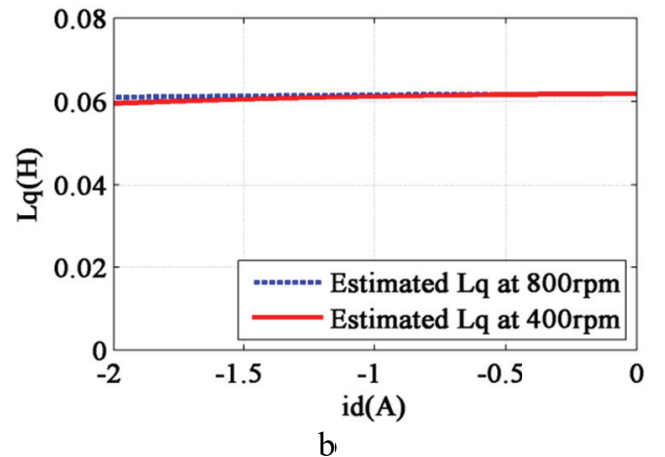

b

Fig. 5. Influence of rotor speed and amplitude of added position offsets.

a Estimated rotor PM flux linkages at different rotor speeds and added position offsets.

b Estimated $q$-axis inductances at different rotor speeds while change in rotor speed is set to 50rpm.

From the design parameter values as shown in Table I, the Motor1 is a salient pole IPMSM while the Motor2 is a non-salient pole SPMSM. For the convenience of analysis, a unit electrical angular $\theta_{u}$ is defined in (18), which corresponds to one pulse of incremental encoder.

$\theta_{u}=\frac{2 \pi \times p}{M}$

where $p$ is the pole pair number of PMSM and $M$ is the maximum number of lines of incremental encoder. For the proposed POPE, the amplitude of the added position offset should be determined according to $M$ of the encoder. For example, as can be seen from Table II, since the term $\omega \psi_{m}$ is usually dominant in the terminal voltage, the term $\psi_{m} \omega \sin (\Delta \theta)$ will be relatively big even if $\Delta \theta<20 \theta_{u}$. Thus, for the POPE test of Motor1, the added position offsets are usually set to $\Delta \theta_{p}=-\Delta \theta_{n}=10 \theta_{u}$ while those are usually set to $\Delta \theta_{p}=-\Delta \theta_{n}=20 \theta_{u}$ for Motor2 $(M=5000)$. A further discussion will be given below.

\subsection{Experimental investigation on Motor1}

The improved POPE is firstly investigated on Motor1, of which the ratio of $L_{q} / L_{d}$ is approximately equal to 2 . For a conventional micro controller, the proposed method only needs a quite short time (tens of milliseconds) to complete the calculation, as shown in (10), (13) and (15). In fact, the time for data measurement is usually much longer than the time for calculation. For a conventional drive, the time for the settling down of currents and voltages usually needs less than $10 \mathrm{~ms}$. Consequently, the time for data recording can be less than $100 \mathrm{~ms}$ in a drive system with high bandwidth current regulators [19]. Besides, for the determination of $q$-axis inductance, it also needs the same time to measure the needed data. Thus, for one load point, it may only take $200 \mathrm{~ms}$ to measure the needed data for the determination of machine parameters at one load point. Thus, for a new PMSM, the time needed for the calculation of parameters at 30 load points will be about 6 s in theory. In this paper, two seconds of data measurement (one second for positive or negative position offset, respectively) at each load point are employed to ensure that the currents and reference voltages have settled down to the stable point after the addition of position 


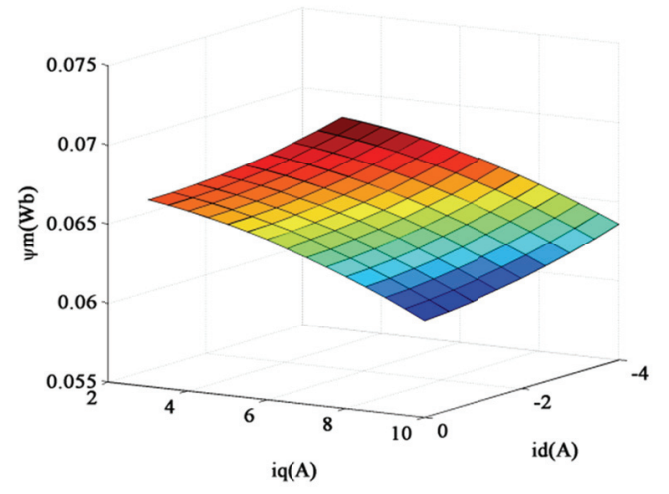

a

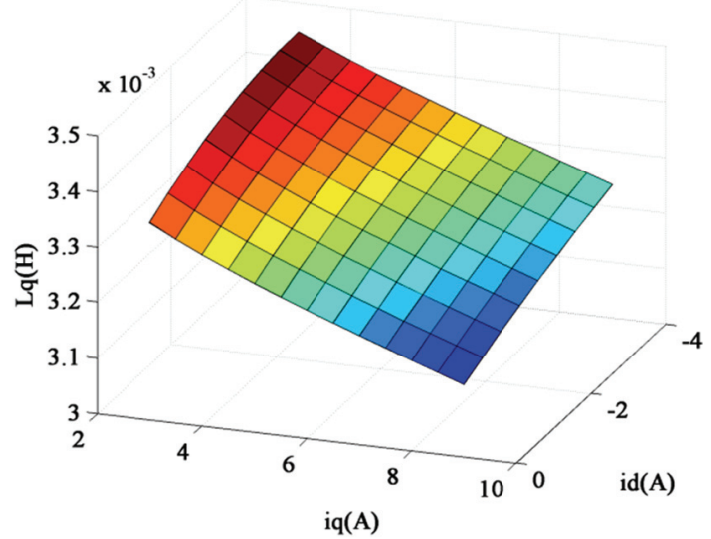

(c)

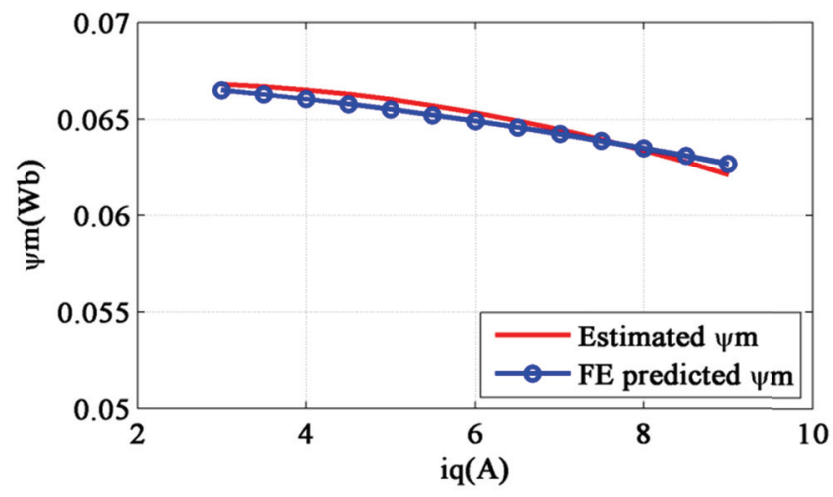

b

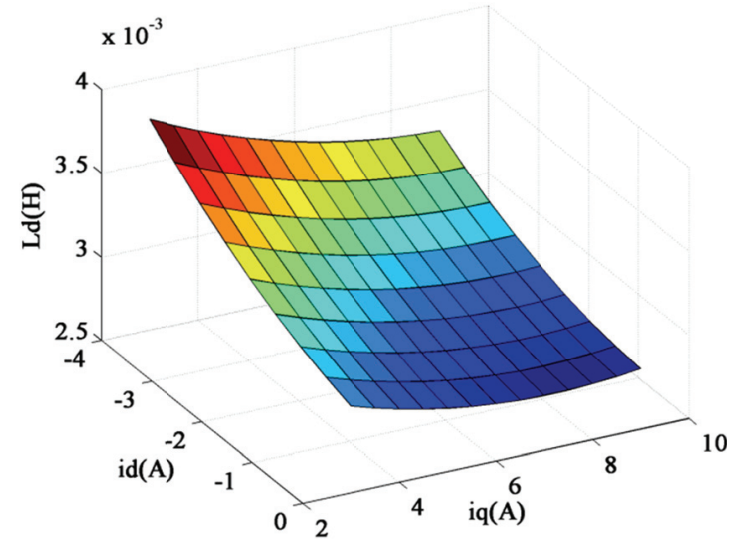

(d)

Fig. 6. POPE estimated PM flux linkages and $d q$-axis inductances under different load conditions (Motor2).

$a$ and $b$ POPE estimated PM flux linkages

$\mathrm{c}$ and $\mathrm{d}$ POPE estimated $d q$-axis inductances

offsets. Thus, for the test of 30 load points of Motor1, the minimum time for the whole process of parameter determination will be about 60 seconds in theory.

Besides, as reported in [4], [22] and [36], the nonideal signal measurement will usually result in a fluctuation in the estimation results due to the ill-conditioned issue. This issue could be mitigated by a surface fitting to the estimation results [28]. Thus, a two-variable quadratic polynomial function (19) is used for the surface fitting of all results throughout this paper.

$f(x, y)=a x+b y+c x^{2}+d y^{2}+e x y+g$

where $x, y$ and $f(x, y)$ correspond to $d$-, q-axis currents and estimated machine parameters such as $d q$-axis inductances, flux linkages and PM flux linkage. $a, b, c, d, e$ and $g$ are constants derived by using the least square regression. For example, for the surface fitting of estimated rotor PM flux linkage, as shown in Fig. 3a, $i_{d}, i_{q}$, and estimated PM flux linkage are regarded as $x, y$, and $f(x, y)$, respectively. As can be seen from Fig. 3a, the estimated PM flux linkage will slightly increase with the amplitude of $i_{d}<0$ due to the demagnetization effect on $d$-axis, whereas it will decrease with the amplitude of $i_{q}$ due to the increasing saturation level. 


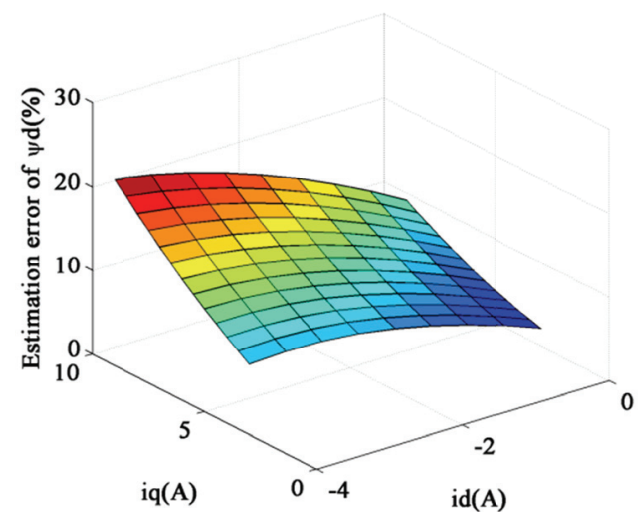

a

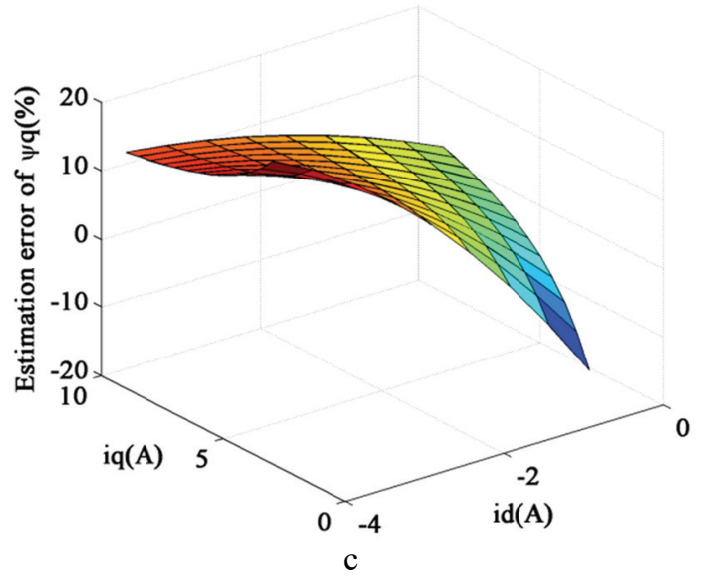

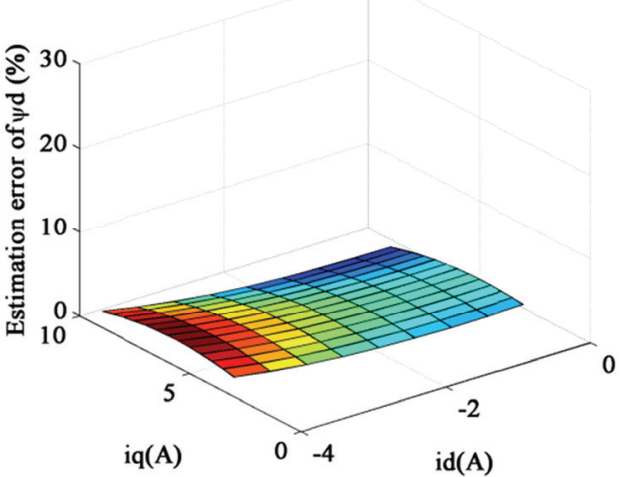

b

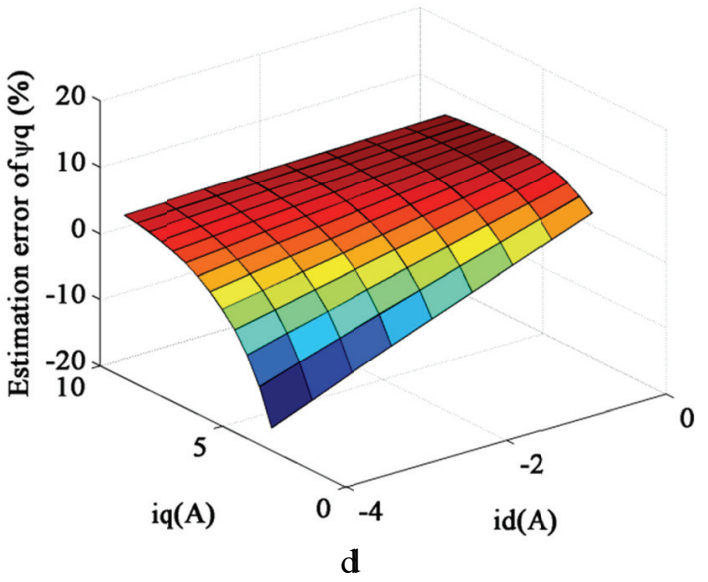

Fig. 7. Difference between estimation and FE results (Motor2).

$\mathrm{a}$ and $\mathrm{c}$ Estimation error of constant speed method compared with FE prediction (MAE of $\Delta \psi_{d}=11.18 \%$, MAE of $\left.\Delta \psi_{q}=10.09 \%\right)$.

$\mathrm{b}$ and $\mathrm{d}$ Estimation error of POPE method compared with FE prediction (MAE of $\Delta \psi_{d}=1.12 \%$, MAE of $\Delta \psi_{q}=4.45 \%$ ).

Table IV Comparison among three sets of test results on Motor2

\begin{tabular}{ccccc}
\hline & & Minimum error & Maximum error & Mean absolute error \\
\hline \multirow{2}{*}{$\begin{array}{c}\text { Constant } \\
\text { speed method }\end{array}$} & $\Delta \psi_{d}$ & $2.09 \%$ & $22.31 \%$ & $11.18 \%$ \\
\cline { 2 - 5 } & $\Delta \psi_{q}$ & $1.38 \%$ & $20.37 \%$ & $10.09 \%$ \\
\cline { 2 - 5 } POPE method & $\Delta \psi_{d}$ & $\leq 0.5 \%$ & $3.18 \%$ & $1.12 \%$ \\
\hline \multirow{2}{*}{$\begin{array}{c}\text { Nominal } \\
\text { value method }\end{array}$} & $\Delta \psi_{q}$ & $1.95 \%$ & $16.61 \%$ & $4.45 \%$ \\
\cline { 2 - 5 } & $\Delta \psi_{d}$ & $6.28 \%$ & $14.43 \%$ & $9.65 \%$ \\
\hline
\end{tabular}

A further comparison is depicted in Fig. 3b, which shows that at $i_{d}=0$, the slope of the estimated PM flux linkage is quite close to that of FE result. Figs. $3 \mathrm{c}$ and $3 \mathrm{~d}$ are the surface fitting results of estimated $d q$-axis inductances under different load conditions. As can be seen from Fig. 3c, the estimated $q$-axis inductance will slightly decrease with the $d$-axis current, which is probably due to the nonideal position measurement and will be analysed in the next section. Meanwhile, as shown in Fig. 3d, the estimated $d$-axis inductance will increase with the amplitude of $i_{d}<0$ due to the demagnetization effect on $d$-axis. Besides, the accuracy of proposed method is further compared with the constant speed method [31], [40], [41], which assumes that the winding resistance is constant and the $d q$-axis flux linkages can be derived from (2) under constant speed test. In order to eliminate the influence of inverter nonlinearity, the method in [31] proposes to approximately estimate the voltage drop due to 
inverter nonlinearity at standstill test and then used to compensate the identified $d q$-axis flux linkages, by which the accuracy of calculated flux linkages can be improved. This scheme will be therefore duplicated in the comparison test shown in Fig. 4 and Table III. Besides, the nominal parameter values listed in Table I are employed to calculate the $d q$-axis flux linkages by (17), which are also compared with the constant speed method and the proposed POPE, as shown in Table III. In Fig. 4, the FE results will be employed as good references to the estimation results, of which the accuracy is ensured and checked by two tests: 1) No-load test. The PMSM is rotated by the load DC machine and its no-load back EMF is then measured from terminal voltage. The amplitude of fundamental component of no-load back EMF is then derived by FFT calculation. The magnet remanence used in FE calculation is then tuned to ensure that the calculated no-load back EMF is almost the same as the measured one.

2) Comparison with standstill tests. The method proposed by Morimoto in [18] is employed to approximately calculate the $d q$ axis incremental inductances at $i_{d}=i_{q}=0$. This method is based on the assumption that the rotor speed at standstill is almost zero during the addition of small zero-mean $d q$-axis high frequency currents.

The above two tests have relatively good accuracy. However, they are only effective at no-load condition or with zero-mean $d q$-axis currents. As can be seen from Fig.4 and Table III, it is found that compared with the FE results, the $d q$-axis flux linkages derived via. (17) by using POPE estimated parameters show much smaller mean absolute errors (MAEs) than those of constant speed method. This can be explained that the constant speed method simply regards the winding resistance and voltage drop due to inverter nonlinearity as constants while the proposed POPE has a higher accuracy thanks to its elimination of their influences during the modelling process. Besides, as shown in Table III, it also has smaller maximum error than the nominal value method.

Furthermore, an investigation on the influence of rotor speeds and amplitudes of added position offsets is given in Fig. 5a. The accuracy of the proposed method depends on the multiply of $\psi_{m}, \omega$, and $\sin (\Delta \theta)$. As the change of $\psi_{m}$ is usually relatively small, the main factor is the right combination of $\omega$ and $\sin (\Delta \theta)$. Thus, in theory, the estimation result at $800 \mathrm{rpm}$ and $\Delta \theta=5 \theta u$ will have almost the same accuracy as that at $400 \mathrm{rpm}$ and $\Delta \theta=10 \theta u$, as shown in Fig. 5a. Thus, in real applications, it is suggested that the voltage change in $d$-axis due to the addition of position offset should be larger than $0.1 \mathrm{~V}$ $\left(\left|\psi_{m} \omega \sin (\Delta \theta)\right| \geq 0.1 \mathrm{~V}\right)$. Besides, for a PMSM, the torque generated by the multiply of $q$-axis current and PM flux linkage is usually dominant. Thus, it is suggested that the added position offset is limited to $\Delta \theta<=8.1^{\circ}$, by which the change in real $q$-axis current will be less than $1 \%\left(\cos \left(8.1^{\circ}\right) \approx 0.99\right)$ and has relatively negligible influence on the output torque and rotor speed. Thus, for the POPE test of Motor1, the added position offsets are set to $\Delta \theta_{p}=-\Delta \theta_{n}=10 \theta_{u}\left(=5.3^{\circ}\right)$ while those are set to 
$\Delta \theta_{p}=-\Delta \theta_{n}=20 \theta_{u}\left(=7.2^{\circ}\right)$ for Motor2 $(M=5000)$. It also should be emphasized that the added position offset will be set back to 0 after the data measurement, which will not influence the output torque afterwards.

Besides, for the identification of rotor PM flux linkage, the rotor speeds and load conditions are at steady state and almost constant during the data measurement. Thus, the iron loss including both eddy current and hysteresis losses will not change during the data measurement. The iron loss is modelled as part of the circuit resistance and its influence has been eliminated during the modelling process, as shown in (8) and (9). Besides, the identification of $L_{q}$ is based on a small change in rotor speed and assuming that the iron loss will be almost constant before and after the speed change. In order to achieve this, the change of rotor speed is limited to ensure that the change in excitation frequency during the data measurement is within $5 \mathrm{~Hz}$, which is relatively small. For example, as depicted in Fig. $5 \mathrm{~b}$, the change in rotor speed is set to $50 \mathrm{rpm}$ which is corresponding to $2.5 \mathrm{~Hz}$ change in excitation frequency of Motor 1 and the estimated $L_{q}$ under 800rpm and 400rpm, respectively, are almost the same with each other, which confirms that the change of iron loss is negligible and its influence can be cancelled in (15).

\subsection{Influence of nonideal position measurement on calculated q-axis inductance}

In the FE model of PMSM, the rotor position can be accurately set up in software. However, in reality, the accuracy of rotor position measurement is usually non-ideal and it may introduce a non-negligible PM flux linkage term into the $d$-axis voltage equation, as shown in (20):

$u_{d}^{*}(k)+D_{d}(k) V_{\text {dead }}=u_{d}(k)=R i_{d}(k)-\omega(k)\left(L_{q} i_{q}(k)+\psi_{m} \sin \left(\Delta \theta_{e}\right)\right)$

where $\Delta \theta_{e} \neq 0$ is the inherent error due to nonideal position measurement. Thus, the PM flux linkage term $\psi_{m} \sin \left(\Delta \theta_{e}\right) \neq 0$ will contribute a non-zero voltage drop to the $d$-axis voltage equation. Thus, in reality, the $q$-axis flux linkage will be:

$\psi_{q}=L_{q} i_{q}+\psi_{m} \sin \left(\Delta \theta_{e}\right)$

The calculated $q$-axis inductance $\hat{L}_{q}$ by (15) will be:

$\hat{L}_{q}=L_{q}+\frac{\psi_{m} \sin \left(\Delta \theta_{e}\right)}{i_{q}}$

On condition that $\Delta \theta_{e}<0$ and $i_{q}$ is fixed as a constant, since the amplitude of $\psi_{m} \sin \left(\Delta \theta_{e}\right)<0$ will slightly increase with the amplitude of $i_{d}<0$, the estimated $q$-axis inductance $\hat{L}_{q}<L_{q}$ will consequently slightly decrease with the amplitude of $i_{d}<0$. This is probably the main reason that the estimated $q$-axis inductance shown in Fig. $3 \mathrm{c}$ decreases with the amplitude of $i_{d}<0$. Besides, it should also be emphasized that the influence of cross coupling effect may also have slight influence on the estimated $q$-axis inductance, especially in deeply-saturated condition. Thus, $\hat{L}_{q}$ can be regarded as a lumped parameter representing the total 


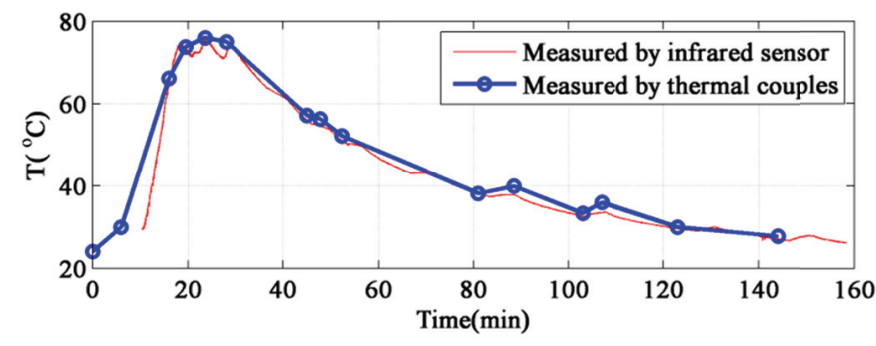

a

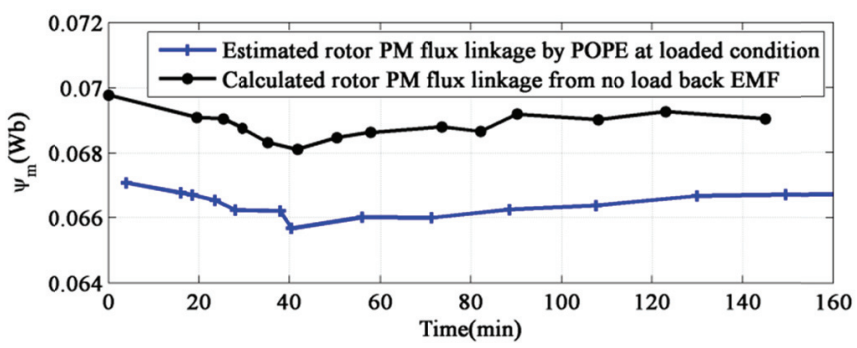

b)

Fig. 8. Variation of estimated rotor PM flux linkage (Motor2).

a Temperatures measured by stator thermal couples and infrared sensor, respectively

$\mathrm{b}$ Estimated and measured rotor PM flux linkages at loaded $\left(i_{q}=4 \mathrm{~A}\right)$ and no-load conditions, respectively

contributions of apparent self-inductance, cross coupling effect and $\psi_{m} \sin \left(\Delta \theta_{e}\right)$. The use of estimated $q$-axis flux linkage (21) including all flux terms in $q$-axis will be therefore more practical in real applications. Nevertheless, for an ideal FE model of PMSM, the $q$-axis inductance will usually increase with the amplitude of $i_{d}<0$ and decrease with the amplitude of $i_{q}$.

\subsection{Experimental investigation on Motor2}

The proposed method is then investigated on Motor2, which is a non-salient pole SPMSM. Fig. 6 shows the surface fitting results of POPE estimated $d q$-axis inductances and rotor PM flux linkage under different load conditions and it is noteworthy that the cross coupling effect of Motor2 is quite negligible. Fig. 6a is the surface fitting result of estimated rotor PM flux linkage under different load conditions, which shows that the PM flux linkage increases with the amplitude of $i_{d}<0$ while it decreases with the amplitude of $i_{q}$. Fig. 6b is a comparison between the POPE estimated and the FE predicted PM flux linkages with reference to $i_{q}$ while $i_{d}=0$. It is obvious that the slope of the estimated rotor PM flux linkage is quite close to that of FE result. Besides, as shown in Fig. 6c, the estimated $L_{q}$ slightly decreases with the amplitude of $i_{q}$ while it slightly increases with the amplitude of $i_{d}<0$. This trend is different from that of Motor1 and it can be explained that the influence of nonideal position measurement is relatively negligible due to the higher accuracy of the encoder mounted on the Motor2. Meanwhile, the surface fitting result of estimated $d$-axis inductance, as shown in Fig. 6d, increases with the amplitude of $i_{d}<0$ while it slightly decreases with the amplitude of $i_{q}$, which is the same as that of Motor1.

In order to evaluate the accuracy, a comparison between the proposed method and the constant speed method is given in Fig. 7. Similarly, a further comparison with the nominal value method is also given in Table IV. Similar to the results shown in Fig. 4, it is obvious that compared with the FE results, the $d q$-axis flux linkages derived via (17) by using POPE estimated parameters can achieve much smaller MAEs than those of constant speed method, which can be explained that the proposed method has cancelled the influence of inverter nonlinearity and circuit resistance during the modelling process and a higher accuracy of identification can be consequently achieved. Besides, it is also noteworthy that the proposed POPE shows relatively large error at some points compared with FE results. It can be explained that the influence of nonideal position measurement would be significant at relatively small $i_{q}$. As can be seen from (21), the real $q$-axis flux linkage is a summation of $L_{q} i_{q}$ and $\psi_{m} \sin \left(\Delta \theta_{e}\right)$. 
Usually, $\Delta \theta_{e}$ is set to 0 in FE calculation while $\Delta \theta_{e} \neq 0$ in real application. Thus, as can be seen from Fig. 4(d) and Fig. 7(d), the difference between the proposed POPE and FE results is relatively big when $i_{q}$ is relatively small. Besides, it is also obvious that this difference will slightly increase with the amplitude of $i_{d}<0$ because the amplitude of $\psi_{m} \sin \left(\Delta \theta_{e}\right)$ also increases with the amplitude of $i_{d}<0$. Nevertheless, the influence of nonideal position measurement is negligible in the determination of $d$-axis flux linkage because $\psi_{d}=L_{d} i_{d}+\psi_{m} \cos \left(\Delta \theta_{e}\right)$ is almost equal to $L_{d} i_{d}+\psi_{m}$. That's the reason why the difference between the POPE estimated and FE predicted $d$-axis flux linkages is always quite small.

Besides, in order to test the performance of online tracking the variation of PM flux linkage with reference to PM temperature, a heater is employed to heat the Motor2 from outside for 25 minutes. A set of thermocouples are buried into the stator winding and an infrared sensor is buried into the cap of stator to online measure the PM temperature from the axial direction. As can be seen from Fig. 8a, it is interesting that the curves of two sets of temperatures are almost the same. It is probable that the infrared sensor is influenced by the temperature rise of the stator cap, whose temperature is quite close to the stator shell. Fig. $8 \mathrm{~b}$ shows the comparison between the estimated and calculated rotor PM flux linkages at loaded and no-load conditions, respectively. It is obvious that the variation trend of calculated rotor PM flux linkage (from back EMF) at no load condition is almost the same as that of the estimated rotor PM flux linkage at loaded condition. The gap between the two sets of curves is due to the saturation resulting from the current excitation. Besides, the peak value of temperature is at about $\mathrm{t}=25 \mathrm{~min}$ while the valley value of PM flux linkage is at about $\mathrm{t}=40 \mathrm{~min}$. This can be explained that there is a delay of heat transfer between the stator and the rotor PMs.

Thus, the proposed method has good performance in online tracking the variation of rotor PM flux linkage due to temperature rise and saturation, and this feature is quite important in torque production [37]-[39] and monitoring the temperature of PMs. Furthermore, its application to drive controls such as MTPA and FW [1] is also promising.

\section{Conclusion}

This paper proposes an improved POPE for the parameter determination of PMSM under different load conditions, which can identify the total $d q$-axis flux linkages, and also the PM flux linkage separately by the addition of two position offsets. This scheme has eliminated the influence of winding resistance and inverter nonlinearity during the modeling process and its performance has been validated on a non-salient pole SPMSM and a salient pole IPMSM, respectively. It shows a good agreement with the FE results and is able to track the variation of PM flux linkage due to temperature rise and saturation. Thus, it is quite promising in online condition monitoring of PMs. However, since the contribution of cross coupling terms to the voltage equation of PMSM is usually overwhelmed by other parameter terms, their separation from the $d q$-axis voltages will be full of challenges and a further development will be the priority of future work. 


\section{References}

[1] Morimoto, S., Takeda, Y., Hirasa, T., Taniguchi, K.: 'Expansion of operating limits for permanent magnet motor by current vector control considering inverter capacity’, IEEE Trans. Ind. Applicat., 1990, 26, (5), pp. 866 -871

[2] Huang, W., Zhang, Y., Zhang, X., Sun, G.: 'Accurate torque control of interior permanent magnet synchronous machine', IEEE Trans. Energy Convers., 1990, 26, (5), pp. 866 -871

[3] Uddin, M.N., Chy, M.M.I.: 'Online parameter-estimation-based speed control of PM AC motor drive in flux-weakening region', IEEE Trans. Ind. Applicat., 2010, 44, (5), pp. 1486-1494

[4] $\mathrm{Xu}, \mathrm{W}$., Lorenz, R.D.: 'High-Frequency injection-based stator flux linkage and torque estimation for DB-DTFC implementation on IPMSMs considering cross-saturation effects', IEEE Trans. Ind. Applicat., 2014, 50, (6), pp. 3805-3815

[5] Guglielmi, P., Pastorelli, M., Pellegrino, G., Vagati, A.: 'Position-sensorless control of permanent-magnet-assisted synchronous reluctance motor', IEEE Trans. Ind. Applicat., 2004, 40, (2), pp. 615-622

[6] Guglielmi, P., Pastorelli, M., Vagati, A.: 'Impact of cross-saturation in sensorless control of transverse-laminated synchronous reluctance motors', IEEE Trans. Ind. Electron., 2006, 53, (2), pp. 429-439.

[7] Guglielmi, P., Pastorelli, M., Vagati, A.: 'Cross-saturation effects in IPM motors and related impact on sensorless control', IEEE Trans. Ind. Applicat., 2006, 42, (6), pp. 1516-1522

[8] Bolognani, S., Zigliotto, M., Unterkofler, K.: 'On-line parameter commissioning in sensorless PMSM drives', in Proc. Of IEEE International Symposium on Ind. Electron., 1997, pp. 480-484

[9] Briz, F., Degner, M.W., Guerrero, J.M., Diez, A.B.: 'Temperature estimation in inverter-fed machines using highfrequency carrier signal injection', IEEE Trans. Ind. Applicat., 2008, 44, (3), pp. 799-808

[10] Briz, F., Degner, M.W., Diez, A.B., Lorenz, R.D.: 'Measuring, modeling, and decoupling of saturation-induced saliencies in carrier-signal injection-based sensorless AC drives', IEEE Trans. Ind. Applicat., 2001, 37, (5), pp. 799-808

[11] Reigosa, D.D., Briz, F., Gacia, P., Guerrero, J.M., Degner, M.W.: 'Magnet temperature estimation in surface PM machines using high-frequency signal injection', IEEE Trans. Ind. Applicat., 2010, 46, (4), pp. 1468-1475

[12] Senjyu, T., Kinjo, K., Urasaki, N., Uezato, K.: 'Parameter measurement for PMSM using adaptive identification', in Proc. IEEE International Symposium on Ind. Electron., 2002, 3, pp. 711-716

[13] Liu, K., Zhu, Z.Q.: 'Parameter estimation of PMSM for aiding PI regulator design of field oriented conrol', in Proc. International Conf. on Electrical Machines and Systems, 2014, pp. 2705-2711

[14] Liu, K., Zhang, Q., Chen, J.T., Zhu, Z.Q., Zhang, J., Shen, A.W.: 'Online multi-parameter estimation of non-salient pole PM synchronous machines with temperature variation tracking', IEEE Trans. Ind. Electron., 2011, 58, (5), pp. 1776-1788

[15] Boileau, T., Leboeuf, N., Nahid-Mobarakeh, B., Meibody-Tabar, F.: 'Online identification of PMSM parameters: parameter identifiability and estimator comparative study', IEEE Trans. Ind. Applicat., 2011, 47, (4), pp. 1944-1957

[16] Wilson, S.D., Stewart, P.G., Taylor, B.P.: 'Methods of resistance estimation in permanent magnet synchronous motors for real-time thermal management', IEEE Trans. Energy Convers., 2008, 25, (3), pp. 698-707

[17] Underwood, S., Husain, I., 'On-line parameter estimation and adaptive control of permanent magnet synchronous machines', IEEE Trans. Ind. Electron., 2010, 57, (7), pp. 2435-2443

[18] Morimoto, S., Sanada, M., Yakeda, Y.: 'Mechanical sensorless drives of IPMSM with online parameter identification', IEEE Trans. Ind. Applicat., 2006, 42, (5), pp. 1241-1248

[19]Liu, K., Zhu, Z.Q.: 'Position offset based parameter estimation using the Adaline NN for condition monitoring of permanent magnet synchronous machines', IEEE Trans. Ind. Electron., 2015, 62, (1), pp. 2372-2383

[20] Liu, K., Zhu, Z.Q.: 'Position offset based parameter estimation for permanent magnet synchronous machines under variable speed control', IEEE Trans. Power Electron., 2015, 30, (6), pp. 3438-3446

[21] Schaible, U., Szabados, B.,: 'Dynamic motor parameter identification for high speed flux weakening operation of brushless permanent magnet synchronous machines’, IEEE Trans. Energy Convers., 1999, 14, (3), pp. 486-492.

[22] Jabbar, M.A., Dong, J., Liu, Z.: 'Determination of machine parameters for internal permanent magnet synchronous motors', in Proc. Power Electron., Mach. and Drives, 2004, 2, pp. 805-810.

[23] Chalmers, B.J., Hamed, S.A., Baines, G.D.: 'Parameters and performance of a high-field permanent-magnet synchronous motor for variable-frequency operation', IEE Proc., 1985, 132, Pt. B, (3), pp. 117-124

[24] Rahman, M.A., Zhou, P., 'Analysis of brushless permanent magnet synchronous motors', IEEE Trans. Ind. Electron., 1996, $43,(2)$, pp. $256-267$

[25] Ichikawa, S., Tomita, M., Doki, S., Okuma, S.: 'Sensorless control of permanent-magnet synchronous motors using online parameter identification based on system identification theory', IEEE Trans. Ind. Electron., 2006, 53, (2), pp. 363-372

[26] Qi, G., Chen, J.T., Zhu, Z.Q., Howe, D., Zhou, L.B., Gu, C.L.: 'Influence of skew and cross-coupling on flux-weakening performance of permanent-magnet brushless AC machines', IEEE Trans. Magnetics, 2009, 45, (5), pp. $2110-2117$

[27] Bianchi, N., Bolognani, S.: 'Magnetic models of saturated interior permanent magnet motors based on finite element analysis,' in Proc. IEEE Ind. Applicat. Conf., Oct. 1998, pp. 27-34 
[28] Stumberger, B., Stumerger, G., Dolinar, D., Hamler, A., Trlep, M.: 'Evaluation of saturation and cross-magnetization effects in interior permanent-magnet synchronous motor', IEEE Tran. Ind. Applicat., 2003, vol. 39, no. 5, pp. 1264-1271

[29] Stumerger, G., Stumberger, B., Dolinar, D.: 'Identification of linear synchronous reluctance motor parameters', IEEE Tran. Ind. Applicat., 2004, 40, (5), pp. 1317-1324

[30] Armando, E., Bojoi, R.I., Gulielmi, P., Pellegrino, G., Pastorelli, M.: 'Experimental identification of the magnetic model of synchronous machines', IEEE Trans. Ind. Applicat., 2013, 49, (5), pp. 2116-2125

[31] Pellegrino, G., Boazzo, B., Jahns, T.M.: 'Magnetic model self-identification for PM synchronous machine drives', IEEE Trans. Ind. Applicat., 2015, 51, (3), pp. 2246-2254

[32] Odhano, S.A., Bojoi, R., Rosu, S.G., Tenconi, A.: 'Identification of the magnetic model of permanent-magnet synchronous machines using DC-biased low-frequency AC signal injection’, IEEE Trans. Ind. Applicat., 2015, 51, (4), pp. 3208-3215

[33] Kim, H. S., Kim, K. H., Youn, M. J.: 'On-line dead-time compensation method based on time delay control', IEEE Trans. Contr. Syst. Technol., 2003, 11, (2), pp. 279-285

[34] Kim, H.W., Youn, M.J., Cho, K.Y., Kim, H.S.: 'Nonlinearity estimation and compensation of PWM VSI for PMSM under resistance and flux linkage uncertainty', IEEE Trans. Contr. Syst. Technol., 2006, 14, (4), pp. 589-601

[35] Bedetti, N., Calligaro, S., Petrella, R.: 'Self-commissioning of inverter dead-time compensation by multiple linear regression based on a physical model', IEEE Trans. Ind. Applicat., 2015, 51, (5), pp. 3954-3964

[36] Kim, H., Hartwig, J., Lorenz, R.D.: 'Using on-line parameter estimation of improve efficiency of IPM machine drives', in Proc. of Power Electron. Specialists Conf., 2002, 2, pp. 815-820

[37] Chu, W.Q., Zhu, Z.Q.: 'Average torque seperation in permanent magnet synchronous machines using frozen permeability', IEEE Trans. Magnetics, 2013, 49, (3), pp. 1202-1210

[38] Sebastian, T.: 'Temperature effects on torque production and efficiency of PM motors using NdFeB Magnets', IEEE Trans. Ind. Applicat., 1995, 31, (2), pp. 353-357

[39] Kim, Y.S., Sul, S.K.: 'Torque control strategy of an IPMSM considering the flux variation of the permanent magnet', in Proc. of 42nd IAS Annual Meeting of Ind. Applicat. Conf., 2007, pp.1301-1307

[40] R. Dutta, M.F. Rahman, "A comparative analysis of two test methods of measuring $d$ - and $q$-axes inductances of interior permanent-magnet machine," IEEE Trans. Magnetics, vol. 42, no. 11, pp. 3712-3718, Nov. 2006.

[41] K.M. Rahman, and S. Hiti, "Identification of machine parameters of a synchronous motor," IEEE Trans. Applicat., vol. 41, no. 2, pp. 557-565, Mar./Apr. 2005. 